\title{
A CLINICAL STUDY COMPARING THE EFFICACY OF EPIDURAL ROPIVACAINE 0.75\% AND LEVOBUPIVACAINE 0.5\% IN LOWER ABDOMINAL SURGERIES
}

\author{
Rajkumar Reddy Inugala1, Sravan Kumar G
}

${ }^{1}$ Assistant Professor, Department of Anaesthesiology, Kakatiya Medical College/MGM Hospital, Warangal, Telangana State. ${ }^{2}$ Assistant Professor, Department of Anaesthesiology, Kakatiya Medical College/MGM Hospital, Warangal, Telangana State.

\section{ABSTRACT}

In 1853, Regional anaesthesia first came into existence when Alexander Wood introduced hollow needle and syringe for drug administration. Regional Anaesthetic techniques are emerging as choice of anaesthesia, because they are relatively inexpensive and easy to administer compared to general anaesthesia. Regional anaesthesia is currently the most effective method of reducing the stress response, especially in patients with surgical procedures involving the lower part of the body.

\section{AIMS AND OBJECTIVES}

The aim of the present study is to compare the effectiveness of Levobupivacaine $0.5 \%$ and Ropivacaine $0.75 \%$ in a volume of 20 $\mathrm{mL}$ in epidural neuraxial blockade in 100 patients undergoing elective lower abdominal surgeries.

\section{PATIENT AND METHODS}

The study was prospective randomised, double-blinded controlled study to evaluate the efficacy of Levobupivacaine $0.5 \%$ and Ropivacaine $0.75 \%$ in epidural route in adult patients undergoing lower abdominal surgeries. This study was carried out in the Department of Anaesthesiology, Mahatma Gandhi Memorial Hospital, Kakatiya Medical College, Warangal from December 2013 to August 2015. The study was approved by the Institutional Ethical Committee. The protocol of the study was reviewed and approved by Dr. NTR University of Health Sciences, Vijayawada.

\section{OBSERVATION AND RESULTS}

Of the 100 patients, 50 belong to Group LB (20 mL of $0.5 \%$ Levobupivacaine) and 50 patients belong to Group $\mathrm{R}(20 \mathrm{~mL}$ of $0.75 \%$ Ropivacaine).

\section{DISCUSSION}

Regional Anaesthesia has always been associated with excellent outcomes in more than 95\% of patients posted for various surgical procedures. Its importance has been recognised not only by the anaesthesiologists, but also by the surgeons. Hence, there is a rapid increase in the usage of regional techniques like spinal, epidural, peripheral nerve blocks, plexus blocks, field blocks, etc.

\section{CONCLUSION}

Both Levobupivacaine and Ropivacaine are relatively new long-acting amide local anaesthetics. Both are pure S-enantiomers of the parent drug Racemic Bupivacaine. Little is known about the comparative efficacy of epidural levobupivacaine with this another widely used long-acting local anaesthetic, ropivacaine.

\section{KEYWORDS}

Anaesthesia, Regional Anaesthetic, Ropivacaine.

HOW TO CITE THIS ARTICLE: Inugala RR, Kumar SG. A clinical study comparing the efficacy of epidural ropivacaine $0.75 \%$ and levobupivacaine $0.5 \%$ in lower abdominal surgeries. J. Evolution Med. Dent. Sci. 2016;5(70):5096-5104, DOI: $10.14260 /$ jemds/2016/1157

\section{INTRODUCTION}

In 1853, Regional anaesthesia first came into existence when Alexander Wood introduced hollow needle and syringe for drug administration. Regional anaesthetic techniques are emerging as choice of anaesthesia, because they are relatively inexpensive and easy to administer compared to general anaesthesia. Regional anaesthesia is currently the most effective method of reducing the stress response, especially in patients with surgical procedures involving the lower part of the body.

Financial or Other, Competing Interest: None.

Submission 14-07-2016, Peer Review 18-08-2016,

Acceptance 24-08-2016, Published 01-09-2016.

Corresponding Author:

Dr. Rajkumar Reddy Inugala,

H.No.1-7-1323, Advocates Colony,

Balasamudram, Hanamkonda,

Warangal- Dist.,

Telangana State.

E-mail: rajkumaringala@gmail.com

DOI: $10.14260 /$ jemds/2016/1157
Epidural anaesthesia is an Anaesthesia obtained by blocking spinal nerves in epidural space as nerves emerge from dura and then pass into the intervertebral foramina. The anaesthetic solution deposited outside the dura therefore differ from spinal anaesthesia.

In 1885, Corning first performed epidural anaesthesia with cocaine for relief of pain in an extremity; it was apparently accidental. In 1921, F. Pages performed extradural anaesthesia in his surgical practice. In 1951, Crawford used peridural anaesthesia for thoracic surgery.

Epidural anaesthesia is the anaesthesia of choice in various surgeries, wherein general or spinal anaesthesia carries a risk. It is a type of regional anaesthesia in which spinal nerves are blocked in the epidural space, as they emerge from dura. Epidural techniques are widely used for operative anaesthesia, obstetric analgesia, post-operative pain control and chronic pain management. Epidural anaesthesia and analgesia are most often performed in the lumbar region. Epidural anaesthesia is preferred to spinal anaesthesia because of the advantages like desired segmental 
blockade, slow and gradual haemodynamic changes, graded level of analgesia provision of postoperative analgesia. Unlike spinal anaesthesia, epidural anaesthesia causes very minimal physiological disturbance. Gastro-intestinal complications such as nausea and vomiting are lower as compared to spinal anaesthesia. Events requiring catheterisation for urinary retention is as low as $1.5 \%$. Avoidance of polypharmacy and airway manipulation along with the postoperative analgesia merits the use of epidural anaesthesia over general anaesthesia in patients undergoing lower abdominal surgeries.

By epidural anaesthesia, the stress response to surgical stimuli such as cardiovascular and pulmonary stress response and immunologic and metabolic dysfunction are reduced. Haematological complications and perioperative blood loss are also reduced by epidural anaesthesia.

Various ester and amide local anaesthetics have been used in Regional Anaesthesia, of which Bupivacaine is most commonly used due to its long duration of action, good intensity of block and satisfactory and long relief from pain.

Bupivacaine, a highly lipophilic long-acting local anaesthetic has been the most commonly used anaesthetic agent in its class to date. Unfortunately, like all amide-type anaesthetics, Bupivacaine has been associated with high rate of cardiac and local toxicity. An important aspect of this toxicity is that it involves stereo-specificity with the $\mathrm{S}(-)$ enantiomer showing significantly less cardiodepressant effects than $\mathrm{R}(+)$ enantiomer.

Based on investigations of the aetiological mechanisms of local anaesthetic-induced cardiotoxicity, the search for less toxic alternatives to Bupivacaine was concentrated, an amide linked agents comprised of a single enantiomer. As a result of these efforts, the long-acting local anaesthetic Ropivacaine which has been recently introduced in India. Ropivacaine is a long-acting regional anaesthetic that is structurally related to Bupivacaine. Thus, Ropivacaine represents the monohydrate of the hydrochloride salt of 1-propyl-2, 6-pipecoloxylidide. Ropivacaine has similar potency to Bupivacaine at doses higher than ED50 for pain relief.

Numerous comparative studies between Ropivacaine and Bupivacaine suggested that Ropivacaine produced less cardiac and central nervous system toxic effects, less motor block and similar duration of action of sensory analgesia. However, with clinical use it was discovered that ropivacaine's latency of sensory analgesia was approximately two-thirds that of bupivacaine. Therefore, it was not as effective in prompting prolonged postoperative analgesia.

Levobupivacaine, the $S$-enantiomer of bupivacaine is the latest local anaesthetic agent introduced into clinical practice. Studies revealed that the R-dextrobupivacaine and the Slevobupivacaine enantiomers of bupivacaine possessed anaesthetic activity, but the S-enantiomer had significantly less cardiac and neural toxic effects than bupivacaine, while still possessing a similar duration of sensory blockade. Levobupivacaine has been shown to be safe and effective for epidural and spinal anaesthesia.

Both Ropivacaine and Levobupivacaine are pure S(-) isomers of the family of n-alkyl-substituted pipecholylxylidides. Their physicochemical properties are quite similar, but the question of their clinical profile has given rise to some controversy. Levobupivacaine, more lipophilic than ropivacaine is theoretically more potent, but because levobupivacaine has only a slightly greater protein binding than ropivacaine ( $95 \%$ vs $90 \%-92 \%$ ), clinical studies do not consistently show a longer duration of action with the S-isomer of bupivacaine.

\section{AIM AND OBJECTIVES}

The aim of the present study is to compare the effectiveness of Levobupivacaine $0.5 \%$ and Ropivacaine $0.75 \%$ in a volume of $20 \mathrm{~mL}$ in epidural neuraxial blockade in 100 patients undergoing elective lower abdominal surgeries.

\section{The Objectives of this Study are}

1. Time for onset of sensory blockade.

2. Time for onset of motor blockade maximum level of sensory blockade.

3. Two segment regression time.

4. Quality of motor blockade.

5. Duration of analgesia.

6. Duration of motor blockade.

7. Haemodynamic parameters.

8. Any adverse effects.

\section{MATERIALS AND METHODS}

\section{Study Design}

The study was prospective randomised, double-blinded controlled study to evaluate the efficacy of Levobupivacaine $0.5 \%$ and Ropivacaine $0.75 \%$ in epidural route in adult patients undergoing lower abdominal surgeries.

\section{Source of Data}

This study was carried out in the Department of Anaesthesiology, Mahatma Gandhi Memorial Hospital, Kakatiya Medical College, Warangal from December 2013 to August 2015. The study was approved by the Institutional Ethical Committee.

\section{METHOD OF COLLECTION OF DATA Sample Size}

A total number of 100 patients, 50 in each group were selected for study; patients were allocated randomly into groups by lottery method.

Group LB, $\mathbf{n}=50$ : Consists of patients who received $20 \mathrm{~mL}$ of Levobupivacaine $0.5 \%$ in epidural route.

Group R, $\mathbf{n}=50$ : Consists of patients who received $20 \mathrm{~mL}$ of Ropivacaine $0.75 \%$ in epidural route.

\section{Inclusion Criteria}

- $\quad$ ASA grade I and II physical status.

- Aged between 18-60 years.

- Of either gender.

- Undergoing lower abdominal surgeries.

- Weighing between $50-70 \mathrm{~kg}$.

- Height within range of 150-170 cm.

\section{Exclusion Criteria}

- Patients not willing to participate in the study.

- $\quad$ Patients with ASA grade III, IV.

- Those with known sensitivity to local anaesthetics.

- Patients with local infection at the site of injection.

- Uncooperative patients.

- Coagulopathies and Bleeding diathesis.

- Raised intracranial tension. 


\section{Emergency Surgeries}

After fulfilling the inclusion and exclusion criteria, the patients were enrolled into the study and informed written consent was obtained from all 100 patients after a detailed explanation of procedure to be performed prior to enrolment.

\section{METHODOLOGY}

\section{Pre-Anaesthetic Evaluation}

During preoperative visit patients detailed history, general physical examination and systemic examination were carried out. Basic demographic data like age, sex, height and weight were recorded.

During pre-anaesthetic checkup, the linear Visual Analogue Scale (VAS) was explained to all patients using 10 cm scale.

\section{PROCEDURE}

The pulse rate, respiratory rate, blood pressure and SpO2 were recorded before starting the case. Peripheral venous cannulation was done with 18G IV cannula and all the patients were preloaded with $10 \mathrm{~mL} / \mathrm{kg}$ Ringer Lactate solution. The patients were placed in left lateral position and under strict aseptic precautions, after local infiltration with $1 \%$ Xylocaine the epidural space was identified with an 18-G Tuohy needle at L3-L4 or L2-L3 interspace, by "loss of resistance" technique; 18G epidural catheter was threaded through the needle into the epidural space for 3-4 cms and secured with adhesive tapes to the back. After negative aspiration for blood and CSF, $3 \mathrm{~mL}$ of $2 \%$ Lignocaine with 15 $\mu \mathrm{gm}$ of adrenaline was given as test dose and the patient was turned to supine position. After 5 mins. if there is no adverse reaction for the test dose, intravascular and intrathecal placement were ruled out (heart rate $\geq 100 \mathrm{bpm}$, systolic blood pressure $<90 \mathrm{mmHg}$ or presence of sensory block) and the study drugs were administered incrementally over a 5 mins. period after negative aspiration for blood and cerebrospinal fluid.

Group LB (n=50), were given $20 \mathrm{~mL}$ of $0.5 \%$ Levobupivacaine epidurally.

Group $\mathbf{R}(\mathbf{n}=\mathbf{5 0})$, were given $20 \mathrm{~mL}$ of $0.75 \%$ Ropivacaine epidurally.

The level of sensory block was assessed by bilateral pinprick method using a blunt tipped 27-G needle at $0.2,5,10$, $15,20,25,30$ and 60 mins. post injection every 30 mins. thereafter until complete regression of sensory block was observed, quality of motor blockade assessed by Modified Bromage Scale at 0, 10, 20 and 30 minute intervals post-dose and subsequently every 30 minutes until the patient returned to a score of zero in both legs. Time of completion of injection was recorded as 0 minute. In the two groups, the following are noted:

1. The onset of sensory blockade at T10 level.

2. Maximum sensory level achieved.

3. Time to attain maximum sensory level.

4. Two segment regression time.

5. Onset of motor blockade.

6. Quality of motor block.

7. Duration of motor block.

8. Duration of analgesia were recorded.
Continuously $\mathrm{Sp02}$, respiratory rate, heart rate were monitored. Haemodynamic variables like SBP, DBP, MAP, pulse rate were recorded every 5 mins. until 30 mins. and at 10 mins. interval thereafter up to 90 mins. and then at 30 mins. interval till the end of surgery. Side effects like nausea, vomiting, bradycardia, hypotension, respiratory depression and shivering were noted in both groups.

\section{Onset Time of Sensory Blockade}

Is taken from the completion of injection of study drug till the patient does not feel the pin prick.

\section{Onset Time of Motor Blockade}

Is taken from the completion of epidural injection of study drug to the time Bromage Grade 0 changed to Grade 1.

\section{Duration of Motor Blockade}

Is taken from the completion of injection of study drug till motor block regresses to Bromage scale 0 .

\section{Duration of Analgesia}

Is taken from the completion of injection of study drug till the patient has VAS (Visual Analogue Scale) score $\geq 4$.

Hypotension was defined as a decrease in SBP of at least $30 \%$ from baseline and was treated with intravenous fluids or vasopressors at the discretion of the attending anaesthesiologist.

If the pulse rate was less than $30 \%$ of baseline, Inj. Atropine $0.6 \mathrm{mg}$ IV was given. If respiratory rate was less than $10 /$ mins., respiratory depression was diagnosed.

At the end of the surgery, the patients were shifted to post-operative ward. They were monitored for every 30 mins. for the first six hours and thereafter every hour for 24 hours period. Pain was managed with top up of $10 \mathrm{~mL}$ of $0.25 \%$ Levobupivacaine.

\section{Statistical Data}

At the end of the study, all the data is compiled and statistically analysed using:

- Diagrammatic representation.

- Descriptive data presented as mean \pm SD.

- Continuous data analysed by paired or unpaired " $\mathrm{t}$ " test.

- Chi-square test and Fischer Exact Probability test to analyse incidence data and thereby statistical difference between the two groups.

- Statistical software namely GraphPad, QuickCalc, VassarStats net was used for analysis of data and Microsoft Word and Excel have been used to generate graphs, tables, etc.

$P$ value $<0.05$ is taken as statistically significant.

$P$ value $>0.05$ is taken as statistically not significant.

\section{OBSERVATION AND RESULTS}

Of the 100 patients, 50 belong to Group LB (20 mL of $0.5 \%$ Levobupivacaine) and 50 patients belong to Group R (20 mL of $0.75 \%$ Ropivacaine).

\section{Age Distribution \\ The age distribution in group LB was 21-60 years, group $\mathrm{R}$ was 22-60 years, and the mean age distribution was comparable and there is no statistical significance $(\mathrm{p}=0.0536) * 3$}




\begin{tabular}{|c|c|c|}
\hline Age in Years & Group LB & Group R \\
\hline $18-25$ & 10 & 10 \\
\hline $26-35$ & 10 & 12 \\
\hline $36-60$ & 30 & 28 \\
\hline Mean & 42.44 & 37.00 \\
\hline SD & 14.44 & 13.38 \\
\hline \multicolumn{3}{|c|}{ Table 1 } \\
\hline
\end{tabular}

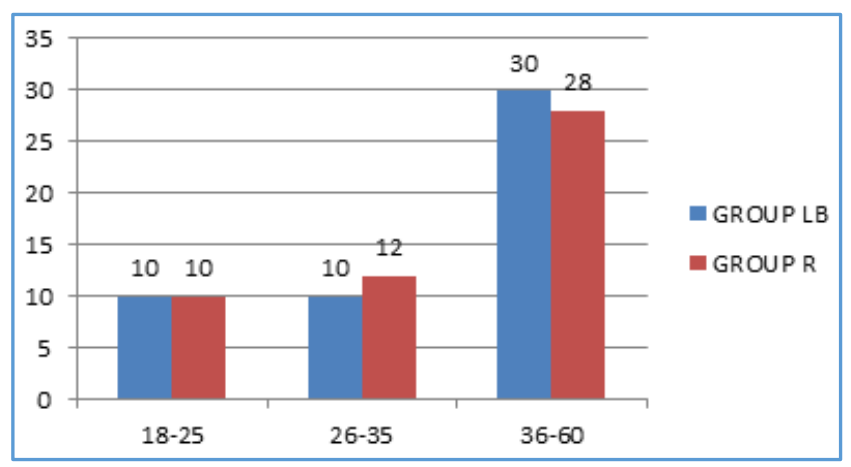

Graph 1: Age Distribution

Height Distribution

The mean height in both groups was comparable, there is no statistical significance, $\mathrm{p}=0.4934^{*}$

\begin{tabular}{|c|c|c|}
\hline Height in cms & Group LB (n=50) & Group R (n=50) \\
\hline RANGE & $148-166$ & $146-168$ \\
\hline MEAN & 156.44 & 157.16 \\
\hline SD & 4.20 & 6.10 \\
\hline \multicolumn{3}{|c|}{ Table 2: Height Distribution } \\
\hline
\end{tabular}

*unpaired ' $\mathrm{t}$ ' test $\mathrm{p}>0.05$

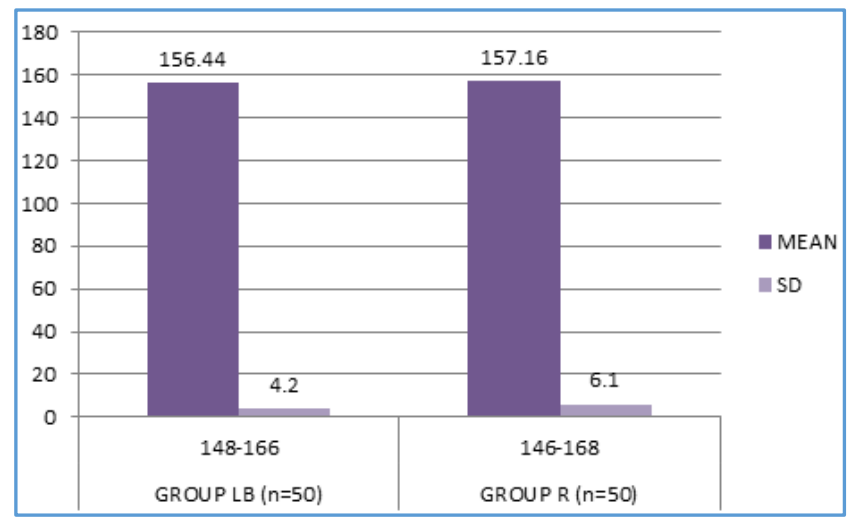

Graph 2: Height Distribution in Cms

\section{Type of Surgery}

The surgeries done were similar in both the groups and statistically comparable ( $\mathrm{p}>0.05)$.

\begin{tabular}{|c|c|c|}
\hline Type of Surgery & Group LB & Group R \\
\hline Hernioplasty & 14 & 12 \\
\hline Incisional hernia mesh repair & 4 & 8 \\
\hline $\begin{array}{c}\text { TAH (Total Abdominal } \\
\text { Hysterectomy) }\end{array}$ & 12 & 8 \\
\hline Open Prostatectomy & 4 & 4 \\
\hline Ovariotomy & 2 & 4 \\
\hline Appendicectomy & 14 & 14 \\
\hline Total & $\mathbf{5 0}$ & $\mathbf{5 0}$ \\
\hline Table 3: Comparison of Surgeries \\
\hline
\end{tabular}

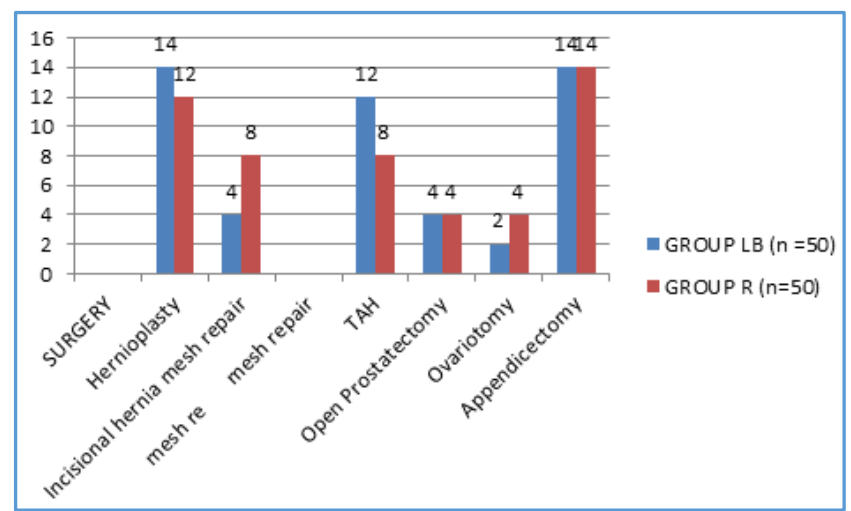

Graph 3: Comparison of Type of Surgeries

\section{Onset of Sensory Blockade}

The mean time of onset of sensory block to T10 level in group LB was $10.0 \pm 3.22$ mins, in group $R$ was $9.0 \pm 2.29$ mins.

In statistical analysis by unpaired ' $\mathrm{t}$ ' test, the difference is considered to be quite not statistically significant $(\mathrm{p}=0.0766)^{*}$

\begin{tabular}{|c|c|c|}
\hline Group & LB (n=50) & R (n=50) \\
\hline MEAN & 10.00 & 9.00 \\
\hline SD & 3.22 & 2.29 \\
\hline \multicolumn{3}{|c|}{$\begin{array}{c}\text { Table 4: Comparison of Mean Time of } \\
\text { Onset of Sensory Blockade }\end{array}$} \\
\hline
\end{tabular}

*unpaired ' $\mathrm{t}$ ' test, $(\mathrm{p}>0.05)$

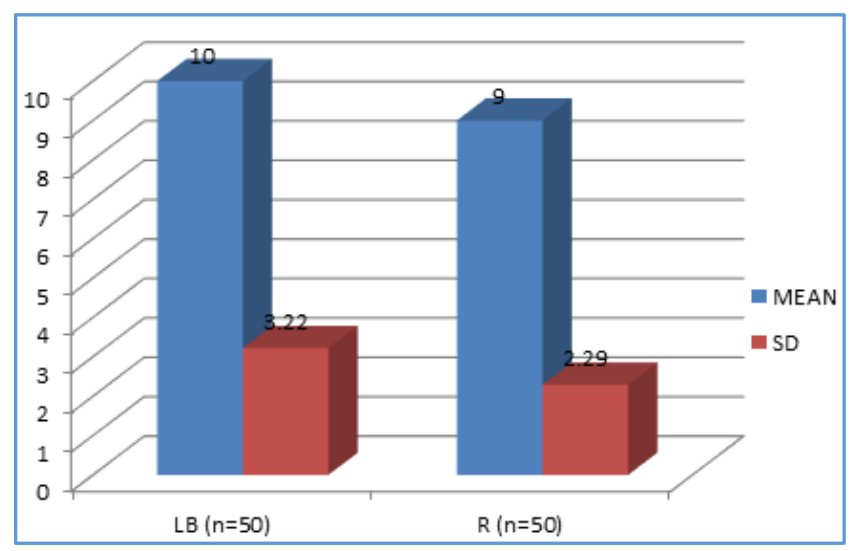

Graph 4: Onset of Sensory Block in Minutes

Highest Sensory Level Achieved

Highest sensory level attained in both groups are shown below. They are statistically not significant $\left(p>0.05^{*}\right)$.

\begin{tabular}{|c|c|c|c|}
\hline Maximum Sensory Level & $\begin{array}{c}\text { Group LB } \\
(\mathbf{n = 5 0})\end{array}$ & $\begin{array}{c}\text { Group R } \\
(\mathbf{n = 5 0})\end{array}$ & Total \\
\hline T4, Count & 6 & 4 & 10 \\
$\%$ & $12 \%$ & $8 \%$ & $10 \%$ \\
\hline T6, Count & 40 & 36 & 76 \\
$\%$ & $80 \%$ & $72 \%$ & $76 \%$ \\
\hline T8, Count & 4 & 10 & 14 \\
$\%$ & $8 \%$ & $20 \%$ & $14 \%$ \\
\hline
\end{tabular}

Table 5: Comparison of Maximum Sensory Level Attained 


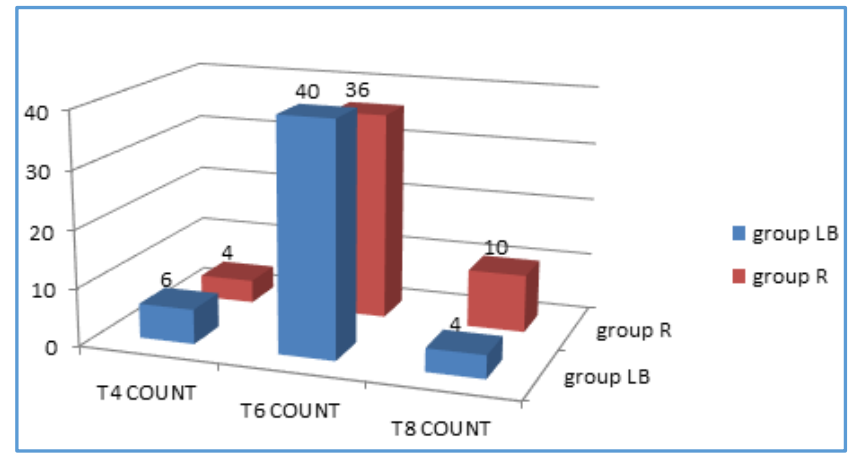

*Fisher's Exact Probability test, $\mathrm{P}_{\mathrm{A}}=0.219, \mathrm{P}_{\mathrm{B}}=0.219(\mathrm{p}>0.05)$

Graph 5: Maximum Sensory Level Achieved

There was no significant difference in the maximum sensory level achieved between the 2 groups as evidenced by table.

\section{Time to Maximum Sensory Level}

The mean time to attain maximum sensory level $15.8 \pm 3.80$ for group LB, $14.52 \pm 2.83$ for group R. P value calculated by unpaired ' $\mathrm{t}$ ' test is $0.0590^{*}$ which is not statistically significant.

\begin{tabular}{|c|c|c|}
\hline Group & LB (n=50) & R (n=50) \\
\hline MEAN & 15.8 & 14.52 \\
\hline SD & 3.80 & 2.83 \\
\hline \multicolumn{3}{|c|}{ Table 6: Comparison of Mean Time } \\
to Attain Maximum Sensory Level
\end{tabular}

*unpaired ' $\mathrm{t}$ ' test, $\mathrm{p}>0.05$

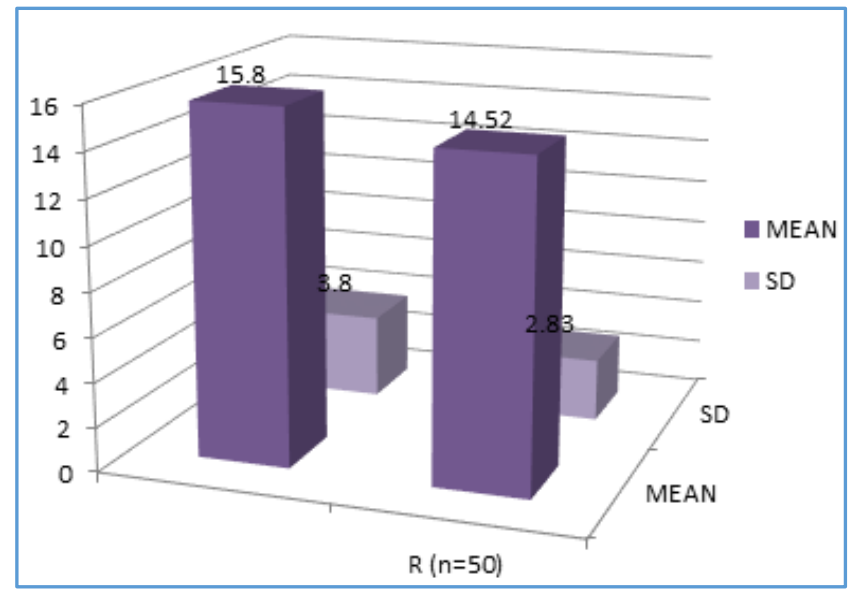

Graph 6: Time to Achieve Maximum Sensory Level in Minutes

\section{Onset of Motor Blockade}

The mean duration of onset of motor blockade in group LB was $22.28 \pm 3.90$, in group R was $21.04 \pm 3.72$ mins.

The statistical analysis by unpaired ' $\mathrm{t}$ ' test showed that there is no statistically significant difference $(p=0.1070)^{*}$ in the two groups.

\begin{tabular}{|c|c|c|}
\hline Group & LB (n=50) & R (n=50) \\
\hline MEAN & 22.28 & 21.04 \\
\hline SD & 3.90 & 3.72 \\
\hline \multicolumn{3}{|c|}{$\begin{array}{c}\text { Table 7: Comparison of Mean Time } \\
\text { of Onset of Motor Blockade }\end{array}$} \\
\hline
\end{tabular}

*unpaired 't' test $\mathrm{p}>0.05$

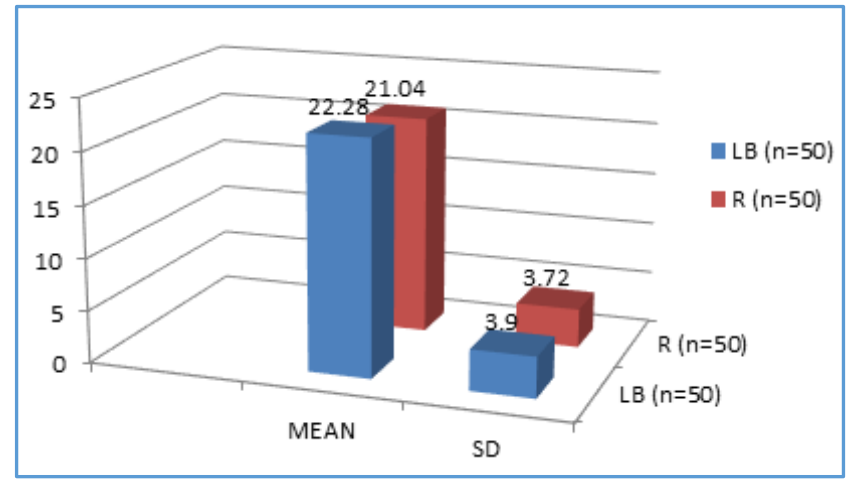

Graph 7: Mean Time of Onset of Motor Blockade in Minutes

\section{Two Segment Regression Time}

The two segment regression time in group LB was $111 \pm 12.95$ mins., in group R $106.60 \pm 11.73$ mins. The statistical analyses by unpaired ' $\mathrm{t}$ ' test showed that there was no statistically significant difference ( $p=0.0714^{*}$ ) between the two groups.

\begin{tabular}{|c|c|c|}
\hline Group & LB (n=50) & R (n=50) \\
\hline MEAN & 111 & 106.60 \\
\hline SD & 12.95 & 11.73 \\
\hline \multicolumn{2}{|c|}{ Table 8: Comparison of Two Segment Regression Time } \\
\hline
\end{tabular}

*unpaired ' $\mathrm{t}$ ' test, $\mathrm{p}>0.05$

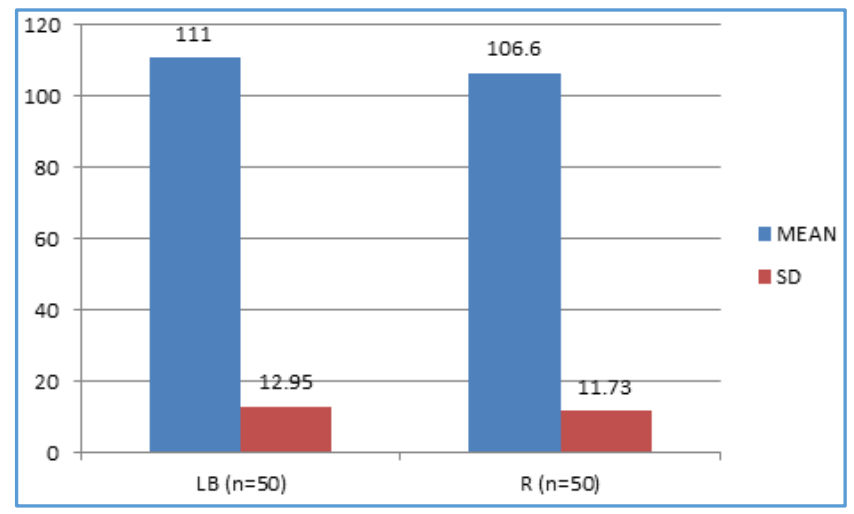

Graph 8: Two Segment Regression Time in Minutes

\section{Duration of Motor Blockade}

The mean duration of motor blockade in group LB was $117.5 \pm 20.42$ mins., in group $\mathrm{R}$ was $125.6 \pm 21.08$ mins.

The statistical analysis by unpaired ' $\mathrm{t}$ ' test showed that there is no statistically significant difference ( $p>0.0538)^{*}$ in the two groups.

\begin{tabular}{|c|c|c|}
\hline Group & LB (n=50) & $\mathbf{R}(\mathbf{n}=\mathbf{5 0})$ \\
\hline MEAN & 117.5 & 125.6 \\
\hline SD & 20.42 & 21.08 \\
\hline \multicolumn{2}{|c|}{ Table 9: Comparison of Duration of Motor Blockade } \\
\hline
\end{tabular}

*unpaired ' $\mathrm{t}$ ' test, $(\mathrm{p}>0.05)$ 


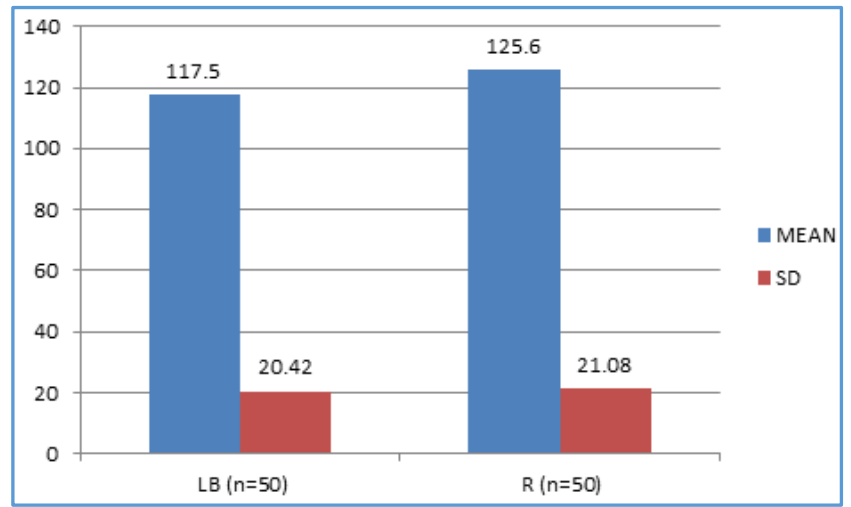

Graph 9: Duration of Motor Blockade in Minutes

\section{Duration of Analgesia}

The mean duration of analgesia in group LB was $229.52 \pm 11.32$, in group $\mathrm{R}$ was $233.48 \pm 10.58$.

The statistical analysis by unpaired ' $\mathrm{t}$ ' test showed that there is no statistically significant difference $(p=0.0738)^{*}$ between the two groups.

\begin{tabular}{|c|c|c|}
\hline Group & LB (n=50) & $\mathbf{R}(\mathbf{n}=\mathbf{5 0})$ \\
\hline MEAN & 229.52 & 233.48 \\
\hline SD & 11.32 & 10.58 \\
\hline \multicolumn{2}{|c|}{ Table 10: Comparison of Duration of Analgesia } \\
\hline
\end{tabular}

*unpaired ' $\mathrm{t}$ ' test, $(\mathrm{p}>0.05)$

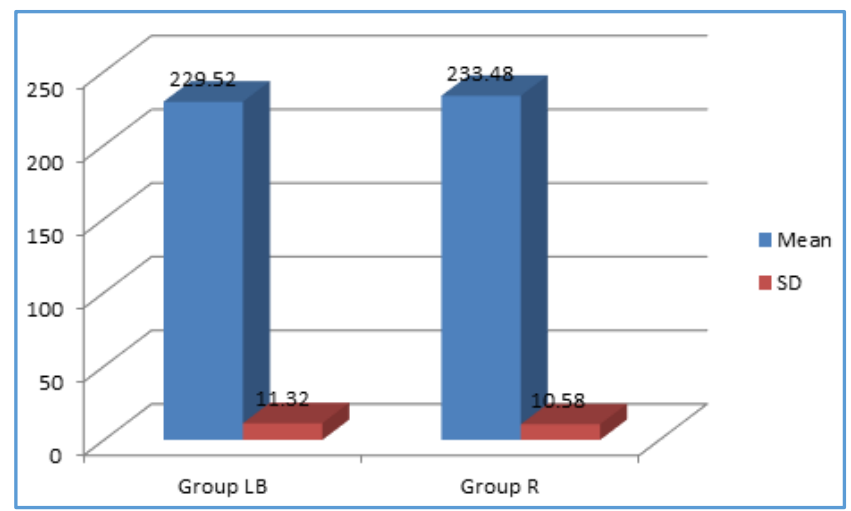

Graph 10: Duration of Analgesia in Minutes

Intraoperative Haemodynamics

\begin{tabular}{|c|c|c|c|}
\hline Minutes & Group LB & Group R & P Value* \\
\hline Basal & $123.36 \pm 18.15$ & $124.16 \pm 11.88$ & 0.7948 \\
\hline 0 & $119.80 \pm 16.69$ & $121.16 \pm 12.78$ & 0.6483 \\
\hline 5 & $119.12 \pm 18.13$ & $115.84 \pm 14.00$ & 0.3138 \\
\hline 10 & $117.96 \pm 15.36$ & $116.40 \pm 12.23$ & 0.5755 \\
\hline 20 & $116.24 \pm 15.59$ & $112.32 \pm 10.33$ & 0.1415 \\
\hline 30 & $116.52 \pm 14.47$ & $112.80 \pm 14.68$ & 0.2049 \\
\hline 40 & $116.32 \pm 14.98$ & $112.36 \pm 15.44$ & 0.1961 \\
\hline 50 & $115.84 \pm 15.91$ & $111.32 \pm 13.86$ & 0.1331 \\
\hline 60 & $116.76 \pm 17.23$ & $111.12 \pm 13.49$ & 0.0714 \\
\hline 70 & $116 \pm 15.28$ & $111.16 \pm 12.02$ & 0.0815 \\
\hline 80 & $116.20 \pm 15.36$ & $110.24 \pm 12.05$ & 0.0529 \\
\hline 90 & $116.32 \pm 16.44$ & $110.20 \pm 12.69$ & 0.0525 \\
\hline \multicolumn{4}{|c}{ Table 11: Comparison of Changes in SBP } \\
\hline
\end{tabular}

*unpaired ' $\mathrm{t}$ ' test $(\mathrm{p}>0.05)$

The changes in systolic blood pressure in both the groups were not significant and were comparable at various time intervals.

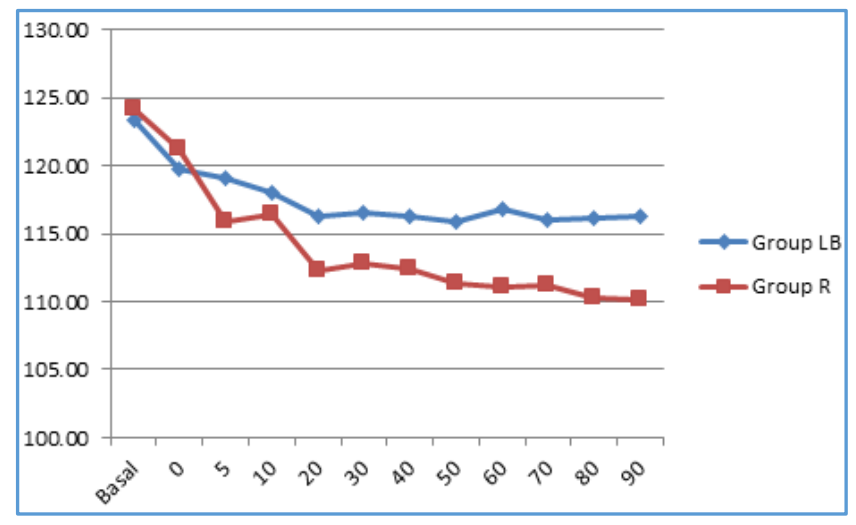

$\mathrm{X}$ axis - minutes, $\mathrm{Y}$ axis - $\mathrm{mmHg}$

Graph 11: Comparison of Changes in SBP

\section{Side Effects}

The incidence of side effects between the 2 groups is statistically comparable.

\begin{tabular}{|c|c|c|c|}
\hline Adverse Effects & Group LB & Group R & Total \\
\hline Nil & 24 & 28 & 52 \\
\hline Hypotension & 12 & 10 & 22 \\
\hline Bradycardia & 12 & 10 & 22 \\
\hline Nausea & 8 & 6 & 14 \\
\hline Vomiting & 4 & 2 & 6 \\
\hline Shivering & 2 & 4 & 6 \\
\hline \multicolumn{2}{|r|}{ Table 12: Comparison of Side Effects } \\
\hline
\end{tabular}

*Fisher Exact Probability test $\mathrm{P}_{\mathrm{A}}=0.99, \mathrm{P}_{\mathrm{B}}=0.82(\mathrm{p}>0.05)$ $\mathrm{X}^{2}=1.05, \mathrm{p}=0.9$

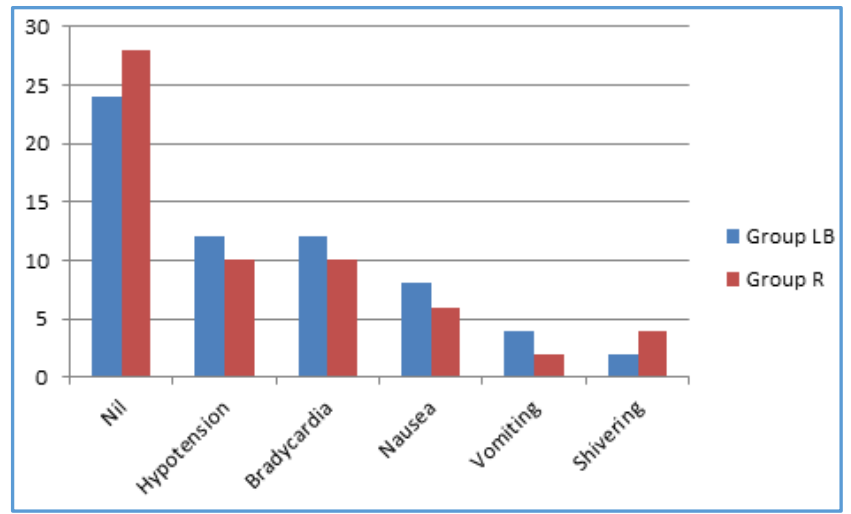

Graph 12: Incidence of Side Effects

\section{DISCUSSION}

Regional anaesthesia has always been associated with excellent outcomes in more than $95 \%$ of patients posted for various surgical procedures. Its importance has been recognised not only by the anaesthesiologists, but also by the surgeons. Hence, there is a rapid increase in the usage of regional techniques like spinal, epidural, peripheral nerve blocks, plexus blocks, field blocks, etc. Thus Regional anaesthesia procedures has become a vital part of the present clinical practice of anaesthesiologists. However, toxicity issues have challenged the history of regional anaesthesia and although great improvements have been made they continue to be an important consideration. ${ }^{1}$

Based on investigations of the aetiological mechanisms of local anaesthetic-induced cardiotoxicity, ${ }^{2}$ the search for less toxic alternatives to Bupivacaine was concentrated on amidelinked agents comprised of a single enantiomer. 
Ropivacaine and Levobupivacaine are relatively recently introduced amino-amide local anaesthetic that are structurally similar to bupivacaine. Ropivacaine is a longacting regional anaesthetic that is structurally related to Bupivacaine. Thus, Ropivacaine represents the monohydrate of the hydrochloride salt of 1-propyl-2, 6-pipecoloxylidide.1,3 Ropivacaine has a lower systemic toxicity than bupivacaine and has a shorter duration of action. ${ }^{4}$

Levobupivacaine, the isolated S(-) enantiomer of bupivacaine has been shown to be less cardiotoxic than bupivacaine in preclinical studies. Owing to the lower affinity of the $\mathrm{S}(-)$ isomer to the cardiac sodium channels compared to the $\mathrm{R}(+)$ isomer, it is associated with less cardiac side effects. Levobupivacaine is the latest local anaesthetic introduced in clinical practice. It is the pure $S(-)$ enantiomer of the racemic formulation, bupivacaine. While both the Rand S-enantiomers of bupivacaine have anaesthetic activity, preclinical studies suggested that levobupivacaine might be less cardiotoxic than the racemic mixture. Although, it has been already compared with racemic bupivacaine for spinal, epidural and peripheral nerve blockade, little is known about the comparative efficacy of epidural levobupivacaine with another widely used long-acting local anaesthetic, ropivacaine. Studies evaluating the minimum local anaesthetic concentration for epidural analgesia during labour demonstrated that levobupivacaine and bupivacaine were nearly equipotent, while ropivacaine was $40-60 \%$ less potent than racemic bupivacaine.

Both Ropivacaine and Levobupivacaine are pure S(-) isomers of the family of n-alkyl-substituted pipecholylxylidides. Their physicochemical properties are quite similar, but the question of their clinical profile has given rise to some controversies. Levobupivacaine, more lipophilic than ropivacaine, is theoretically more potent, but because levobupivacaine has only a slightly greater protein binding than ropivacaine ( $95 \%$ vs $90 \%-92 \%$ ), clinical studies do not consistently show a longer duration of action with the S-isomer of bupivacaine.

The present study was conducted on 100 patients randomly selected and divided into two groups of 50 each. The demographic profile of patients in two groups was comparable with respect to mean age, body weight, height, gender distribution and types of surgeries.

\section{Age}

The mean age of patients in the present study was 42.44 years in Group LB, which received $20 \mathrm{~mL}$ of $0.5 \%$ Levobupivacaine and 37.00 years in Group R, which received $20 \mathrm{~mL}$ of $0.75 \%$ Ropivacaine in epidural route.

\section{Height}

The two groups in the present study were comparable with respect to height. The mean height in Group LB was 156.44 $\mathrm{cm}$ and in Group R it was $157.16 \mathrm{~cm}$.

\section{Weight}

The weight distribution between the two groups were comparable with a mean weight of $57.44 \mathrm{~kg}$ in Group LB and $58.32 \mathrm{~kg}$ in Group R.

In the present study, the mean time of onset of sensory blockade at T10 in Group LB was 10 \pm 3.22 minutes and Group $R$ was $9 \pm 2.29$ minutes $(p=0.0766)$. There is no statistically significant difference in the onset of sensory blockade between the groups ( $\mathrm{p}>0.05)$.

In a study conducted by Concepcion et $\mathrm{al}^{5}{ }^{5}$ where they compared three different concentrations of Ropivacaine $(0.5 \%, 0.75 \%, 1 \%)$, the mean onset time of sensory block for Ropivacaine to T12 was $6.6 \pm 1.7$ mins. compared to the mean onset time of sensory block for Ropivacaine $9 \pm 1.29$ minutes in the present study. The slightly longer onset time of study could be due to taking T10 dermatome as level for onset of sensory block in the present study compared to T12 dermatome in their study.

In a study by Cekmen et al, 6 where they compared epidural Ropivacaine and Bupivacaine in arthroscopic surgeries, the mean onset time to T10 for Ropivacaine was $13.6 \pm 5.1$ as compared to $12.2 \pm 6.5$ for Bupivacaine. The onset time of sensory block for Bupivacaine was longer than onset time of sensory block for Ropivacaine in our study, which could be due to the usage of $15 \mathrm{~mL}$ of $0.5 \%$ Ropivacaine when compared to $20 \mathrm{~mL}$ of $0.75 \%$ Ropivacaine in the present study.

Also the mean onset time of sensory block for Ropivacaine in our study was similar to the mean onset time of sensory block for Ropivacaine in a study conducted by David Brown et al, 7 where they compared 0.5\% Ropivacaine and $0.5 \%$ Bupivacaine for epidural anaesthesia $(10.7 \pm 5.6)$. Here, they used a volume of $20 \mathrm{~mL}$ of local anaesthetic as we did in the present study. In the present study, the duration of analgesia in Group LB was $229.52 \pm 11.32$ minutes and in Group R was $233.48 \pm 10.58$ minutes. There is no statistically significant difference in the duration of analgesia between the groups with a $P$ value of 0.0738 ( $p>0.05$ ).

In a study conducted by Concepcion et al, 5 where they compared three different concentrations of Ropivacaine $(0.5 \%, 0.75 \%, 1 \%)$, the duration of analgesia with $0.75 \%$ Ropivacaine is $255 \pm 73$ minutes, which is similar to our result. In a study by Brockway M.S. et al, ${ }^{8}$ where they compared different concentrations of Ropivacaine $(0.5 \%, 0.75 \%, 1 \%)$ with Bupivacaine $(0.5 \%, 0.75 \%)$, they stated that there is little difference between the groups with respect to speed of onset of sensory block. Duration of analgesia was increased by increasing the concentration of both drugs; this had minimal effect on onset time or extent of block. When same concentration of each drug was administered, there were inconsistent difference in duration of sensory block, none of which was statistically significant. Increasing concentration of both drugs resulted in greater degree and longer duration of motor block. They concluded that Ropivacaine produced slower onset, shorter duration and less intense motor block than same concentration of Bupivacaine.

In the present study, the two segment regression time in Group LB was $111 \pm 12.95$ minutes and in Group $\mathrm{R}$ was $106.6 \pm 11.73$ minutes with no statistically significant difference between the Groups with a $P$ value of 0.0781 ( $p>0.05)$.

In present study, the time taken to attain maximum sensory level in Group LB was 15.8 \pm 3.8 minutes and in Group $\mathrm{R}$ was $14.52 \pm 2.83$ minutes with no statistically significant difference between the Groups with a $P$ value of 0.0590 $(p>0.05)$.

In a study conducted by Kountoudi et al, ${ }^{9}$ where they compared epidural Levobupivacaine $0.5 \%$ with Ropivacaine $0.5 \%$ for inguinal hernia repair procedures in 30 patients, 
there was no difference as far as the level of sensory block is concerned.

In a study conducted by Finucane et al, 10 where they compared different concentrations of Ropivacaine $(0.5 \%$, $0.75 \%$ and $1 \%$ ) and Bupivacaine in concentration of $0.5 \%$ in $25 \mathrm{~mL}$ volume in patient undergoing lower abdominal surgeries with epidural anaesthesia, they observed no difference between the groups in terms of maximum sensory block level. However when duration of motor and sensory block were compared as the Ropivacaine dose was increased, they obtained a significant dose response effect.

In the study conducted by Cox et al, ${ }^{11}$ mean onset time for motor block for Levobupivacaine was 25 minutes versus 17 minutes for Bupivacaine. In the present study the mean onset of motor block for Group LB was 22.28 minutes, which is comparable to this study with respect to modified Bromage scale.

In a study conducted by Peduto et al, ${ }^{12}$ where they compared epidural levobupivacaine $0.5 \%$ with ropivacaine $0.75 \%$ for lower limb procedures, it was concluded that Levobupivacaine $0.5 \%, 15 \mathrm{~mL}$ produces epidural blockade with the same clinical profile as ropivacaine $0.75 \%, 15 \mathrm{~mL}$.

Olofsen, Erik et al ${ }^{13}$ noted that Ropivacaine had lower speed of onset and offset than Levobupivacaine. This may be due to lower lipid solubility of Ropivacaine. It was observed by Karz J A et al,14 that no significant difference was found in motor or sensory effects with $0.5 \%$ Bupivacaine with $0.75 \%$ Ropivacaine given epidurally, which proves their equipotency at different concentration.

The onset of motor block is slower with levobupivacaine (Kopacz et $\mathrm{al}^{15}$ ) and it is less dense compared to Bupivacaine but with similar duration. The quality of motor blockade follows the rank of order Bupivacaine > Levobupivacaine > Ropivacaine according to various studies.

In a study conducted by Senard et al,16 it was concluded that the spread, quality and haemodynamic effects are also similar after equal doses of levobupivacaine and Ropivacaine, self-administered via postoperative patient controlled epidural analgesia, but ropivacaine receiving patients appear to ambulate earlier. In the present study, the duration of motor blockade in Group LB was 117.5 \pm 20.42 minutes and in Group R was $125.6 \pm 21.08$ minutes. There is no statistically significant difference in the duration of motor blockade between the groups with a $P$ value of $0.054(p>0.05)$.

The present study has not shown statistically significant difference between groups in major observed characteristics. Sensory and motor block characteristics were similar between groups in all evaluated parameters except in the intensity of motor block.

Ropivacaine provides satisfactory anaesthesia with minimal blockade of motor function at a concentration of $0.5 \%$. This should be an asset in obstetrical analgesia and anaesthesia where prolonged sensory analgesia with minimal blockade is desirable. An increase in concentration resulted in a more profound motor blockade. ${ }^{5}$

\section{Haemodynamic Changes}

There is no statistically significant difference in heart rate between the two groups at various time intervals ( $p>0.05)$ No patient in either group developed significant bradycardia. There was no statistically significant differences in systolic blood pressure, diastolic blood pressure, mean arterial pressure monitored at various intervals between the two groups. However, 12 patients (24\%) in group LB and 10 patients (20\%) in Group R developed hypotension, which was treated with intravenous fluids and mephentermine. The requirement of vasopressor for maintenance of stable haemodynamic parameters did not reveal any significant difference between both groups on statistical comparison.

\section{Complications}

The intraoperative complications encountered in the present study were hypotension, bradycardia, nausea, vomiting and shivering; $16 \%(n=8)$ of patients in Group LB and $12 \%(n=6)$ of patients in Group R had nausea; $8 \%(n=4)$ of patients in Group LB and 4\% (n=2) of patients in Group R had vomiting; $4 \%(n=2)$ of patients in Group LB and 8\% $(n=4)$ of patients in Group R had shivering; 48\% ( $\mathrm{n}=24)$ of patients in Group LB and $56 \%(n=28)$ patients in Group $\mathrm{R}$ did not develop any intraoperative complications. There was no statistical difference in incidence of complications between the groups.

No episodes of headache, urinary retention and respiratory depression were noted.

Levobupivacaine toxicity is intermediary to ropivacaine and bupivacaine. ${ }^{17,18}$ It seems to have same cardiovascular and neurological effects as compared to Ropivacaine when administered to volunteers. ${ }^{19}$

Equal doses of Levobupivacaine and Ropivacaine provide similar onset of sensory block, maximum cephalic spread and duration of analgesia, but the onset of motor block is delayed and less dense in both drugs.

Levobupivacaine has a wider margin of safety and showed greater differentiation between duration of sensory and motor blockade similar to Ropivacaine. It can be safely used for regional anaesthesia for lower abdominal surgeries. The onset of sensory anaesthesia begins at 10-25 minutes after epidural administration with 2-4 hours duration. 18

\section{SUMMARY AND CONCLUSION}

Both Levobupivacaine and Ropivacaine are relatively new long-acting amide local anaesthetics. Both are pure Senantiomers of the parent drug racemic Bupivacaine. Little is known about the comparative efficacy of epidural levobupivacaine with this another widely used long-acting local anaesthetic, ropivacaine.

Hence, in our study we compared the efficacy of Levobupivacaine $0.5 \%$ with Ropivacaine $0.75 \%$ in epidural route in a volume of $20 \mathrm{~mL}$ in 100 adult patients who were divided into two groups of 50 patients each, belonging to ASA grade 1 and 2 of either gender between the age group of 1860 years undergoing lower abdominal surgeries.

Our study has not shown statistically significant difference between the groups in sensory block characteristics such as mean onset time of sensory blockade, mean time to attain maximum sensory level, maximum level of sensory blockade, two segment regression time and duration of analgesia. Also motor parameters such as mean time of onset of motor block and duration of motor block and quality of motor block were comparable between the groups with a statistically insignificant $\mathrm{P}$ value. With respect to haemodynamic parameters and side effect profiles, both Levobupivacaine and Ropivacaine were comparable.

Both agents demonstrate a distinct separation of sensory and motor fibre blockade when employed as dilute solutions. 
Increase in concentrations of both drugs may result in a more profound degree of motor blockade.

The present study concludes that $0.5 \%$ Levobupivacaine and $0.75 \%$ Ropivacaine were clinically similar with respect to sensory block characteristics and duration of analgesia, quality of motor blockade with minimal side effects in both the groups. Both drugs could be better alternatives to Bupivacaine in epidural anaesthesia.

\section{REFERENCES}

1. Zink W, Graf BM. Benefit-risk assessment of ropivacaine in the management of postoperative pain. Drug Safety 2004;27(14):1093-114.

2. Albright GA. Cardiac arrest following regional anaesthesia with etidocaine and bupivacaine. Anaesthesiology 1979;51(4):285-7.

3. Simpon D, Curran MP, Oldfield V, et al. Ropivacaine: a review of its use in regional anaesthesia and acute pain management. Drugs 2005;65(18):2675-717.

4. Stienstra R. The place of ropivacaine in anaesthesia. Acta Anaesth Belg 2003;54(2):141-8.

5. Concepcion M, Arthur GR, Steele SM, et al. A new local anesthetic, ropivacaine. Its epidural effects in humans. Anesth Analg 1990;70(1):80-5.

6. Cekmen N, Arslan M, Musdal Y, et al. Comparison of the effects of a single dose of epidural ropivacaine and bupivacaine in arthroscopic operations. Medwell Res J Med Sci 2008;2(3):109-15.

7. Brown DL, Carpenter RL, Thompson GE. Comparison of $0.5 \%$ ropivacaine and $0.5 \%$ bupivacaine for epidural anesthesia in patients undergoing lower-extremity surgery. Anesthesiology 1990;72(4):633-6.

8. Brockway MS, Bannister J, McClure JH, et al. Comparison of extradural ropivacaine and bupivacaine. Br J Anaesth 1991;66(1):31-7.

9. Kountoudi M, Papadaki E, Pandazi A, et al. A comparison of epidural levobupivacaine $0.5 \%$ with ropivacaine $0.5 \%$ for inguinal hernia repair procedure: blood pressure and heart rate alternations: a-428. European Journal of Anaesthesia 2004;21(Suppl 32):103.

10. Finucane BT, Sandler AN, McKenna J, et al. A double blind comparison of ropivacaine $0.5,0.75,1.0 \%$ and bupivacaine $0.5 \%$, injected epidurally in patients undergoing abdominal hysterectomy. Can J Anaesth 1996;43(5 Pt 1):442-9.
11. Cox CR, Checketts MR, Mackenzie N, et al. Comparison of $\mathrm{S}(-)$ - bupivacaine with racemic (RS) - bupivacaine in supraclavicular brachial plexus block. $\mathrm{Br} \mathrm{J}$ Anaesth 1998;80(5):594-8.

12. Peduto VA, Baroncini S, Montanini S, et al. A prospective, randomized, double-blind comparison of epidural levobupivacaine $0.5 \%$ with epidural ropivacaine $0.75 \%$ for lower limb procedures. European Journal of Anaesthesia 2003;20(12):979-83.

13. Olofsen E, Burm AG, Simon MJ, et al. Population pharmacokinetic-pharmacodynamic modeling of epidural anaesthesia. Anaesthesiology 2008;109(4): 664-74.

14. Karz JA, Knarr D, Bridenbaugh PO. A double blind comparison of $0.5 \%$ bupivacaine and $0.75 \%$ ropivacaine administered epidurally in humans. Reg Anaesthesia 1990;15(5):250-2.

15. Kopacz DJ, Allen HW, Thompson GE. A comparison of epidural levobupivacaine $0.75 \%$ with racemic bupivacaine for lower abdominal surgery. Anesth Analg 2000;90(3):642-8.

16. Senard M, Kaba A, Jacquemin MJ, et al. Epidural levobupivacaine $0.1 \%$ or ropivacaine $0.1 \%$ combined with morphine provides comparable analgesia after abdominal surgery. Anaesthesia Analg 2004;98(2): 389-94.

17. Morrison S, Dominquez J, Frascarolo P, et al. A comparison of the electrocardiographic cardiotoxic effects of racemic bupivacaine, levobupivacaine and ropivacaine in anaesthetized swine. Anaesthesia Analg 2000;90(6):1308-14.

18. Lim Y, Ocampo CE, Sia AT. A comparison of duration of analgesia of intrathecal $2.5 \mathrm{mg}$ of bupivacaine, ropivacaine and levobupivacaine in combined spinal epidural analgesia for patients in labor. Anesth Analg 2004;98(1):235-9.

19. Graham AC, McClure JH. Quantitative assessment of motor block in laboring women receiving epidural analgesia. Anaesthesia 2001;56(5):470-6. 